\title{
OPTIMIZATION OF SLENDER SYSTEMS BY MEANS OF GENETIC ALGORITHMS
}

\author{
Krzysztof Sokót ${ }^{1}$, Adam Kulawik ${ }^{2}$ \\ ${ }^{I}$ Institute of Mechanics and Machine Design Foundation, Czestochowa University of Technology \\ Częstochowa, Poland \\ ${ }^{2}$ Institute of Computer and Information Sciences Foundation, Czestochowa University of Technology \\ Częstochowa, Poland \\ Isokol@imipkm.pcz.pl, ${ }^{2}$ kulawik@icis.pcz.pl
}

\begin{abstract}
In this paper, the results of numerical studies on optimization of a geometrically nonlinear column with an internal crack by means of genetic algorithms are presented. The system is loaded by an axially applied external force $P$ with a constant line of action. The presented problem is formulated on the basis of the principle of stationary total potential energy. The main purpose of this paper is to investigate an influence upon the localization of the crack and flexural rigidity ratio on critical loading of the system and to find an optimum localization of the crack in order to achieve high loading capacity. In order to calculate optimum values of these parameters the genetic algorithms are implemented into computer program. The artificial method of solution of the problem has been used due to the strongly nonlinear nature of the investigated problem.
\end{abstract}

Keywords: crack, genetic algorithm, optimization, slender system

\section{Introduction}

The study on natural vibration, critical loading and instability of the nonlinear columns and beams subjected to an axially applied load were the subject of numerous scientific investigations and experiments. The first papers have already appeared in the past century.

In this study the problem of optimization of the geometrically nonlinear column consisting of three rods with divergence instability is taken into account. In the investigated system the first element is a continuous rod and the crack has been placed in the connection of rods two and three. The crack size has been modeled by means of a pin and rotational spring with stiffness $C$. The investigated column is loaded by the external force $P$ with constant line of action. The scientific researches of columns with crack were performed by Kukla [1] and Wang [2]. The numerical calculations of divergence instability were performed by Przybylski [3] and Tomski [4]. The problem of instability and natural vibration have been formulated by means of the principle of stationary total potential energy. Aside from analytical models, the numerical ones were also investigated [5-7]. 
The choice of the optimization algorithm is a quite problematic task. The implementation of the greedy algorithm can lead to a local optimum. The selection of deterministic algorithms strongly limits the application. The best choice for the presented task is to select a group of non-deterministic heuristic algorithms [8].

\section{Problem formulation}

In Figure 1 the nonlinear cantilever column under investigation is presented. Member $I$ consists of rod (1), and member $I I$ elements are rods (2) and (3) connected by a pin strengthened by a rotational spring of stiffness $C$. This type of connection models an internal crack in the system. The smaller value of $C$ is the greater crack. The investigated system is loaded by a concentrated axially applied force $P$ in the point of connection of rods (1) and (3). The deflection angles of these rods are identical. The rods have a length $l_{i}=1,2,3$ respectively. The physical structures of the considered system are shown in Figure 2 - a) two coaxial tubes, b) tube and rod, c) flat frame.

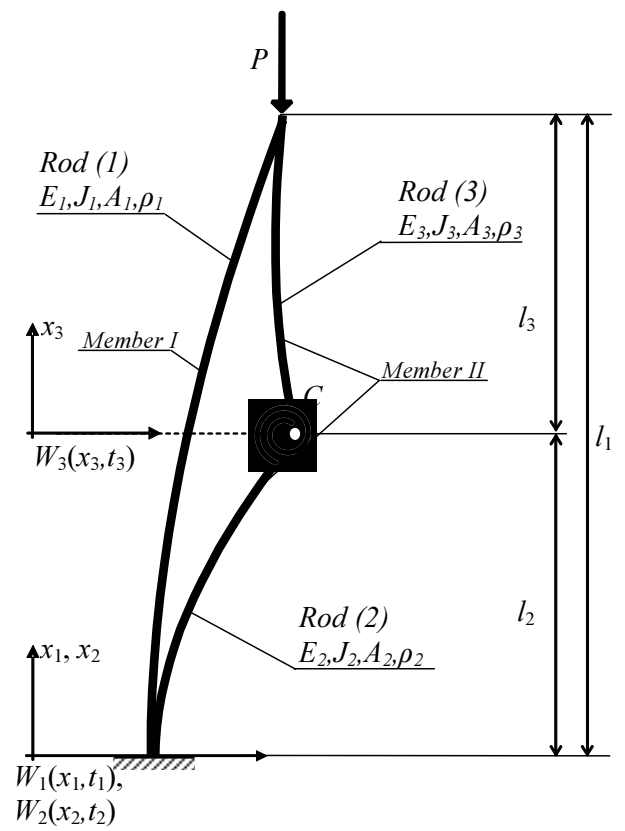

Fig. 1. The nonlinear system under consideration subjected to Euler's load a)
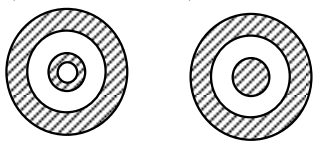

c)
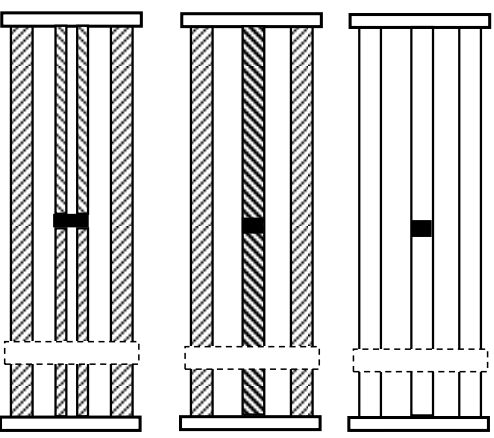

Fig. 2. Exemplary models of real-life structures

The presented problem is formulated on the basis of the principle of stationary total potential energy as follows: 


$$
\begin{gathered}
V=\frac{1}{2}\left\{\sum_{i=1}^{3} \int_{0}^{l_{i}} E_{i} J_{i}\left[\frac{\partial^{2} W_{i}\left(x_{i}, t\right)}{\partial x_{i}^{2}}\right]^{2} d x_{i}+\int_{0}^{l_{i}} E_{i} A_{i}\left[\frac{\partial U_{i}\left(x_{i}, t\right)}{\partial x_{i}}+\frac{1}{2}\left(\frac{\partial W_{i}\left(x_{i}, t\right)}{\partial x_{i}}\right)^{2}\right]^{2} d x_{i}\right\}+ \\
+\frac{1}{2} C\left(\left.\frac{\partial W_{3}\left(x_{3}, t\right)}{\partial x_{3}}\right|_{x_{3}=0}-\left.\frac{\partial W_{2}\left(x_{2}, t\right)}{\partial x_{2}}\right|_{x_{2}=l_{2}}\right)^{2}+P U_{1}\left(l_{1}, t\right)
\end{gathered}
$$

where: $E_{i}$ - Young modulus, $J_{i}$ - moment of inertia, $A_{i}$ - cross-section area, $\rho_{i}$ - density of the material, $C$ - rotational spring stiffness, $P$ - external load.

Equating the first variation of the potential energy to zero, and performing variational and integration operations leads to:

$$
\begin{gathered}
\delta V=\sum_{i=1}^{3}\left\{E_{i} J_{i} \int_{0}^{l_{i}} \frac{\partial^{4} W_{i}\left(x_{i}\right)}{\partial x_{i}^{4}} d x_{i} \delta W_{i}\left(x_{i}\right)+\right. \\
-\left.E_{i} J_{i} \frac{\partial^{3} W_{i}\left(x_{i}\right)}{\partial x_{i}{ }^{3}} \delta W_{i}\left(x_{i}\right)\right|_{0} ^{l_{i}}+\left.E_{i} J_{i} \frac{\partial^{2} W_{i}\left(x_{i}\right)}{\partial x_{i}{ }^{2}} \delta \frac{\partial W_{i}\left(x_{i}\right)}{\partial x_{i}}\right|_{0} ^{l_{i}}+ \\
-E_{i} A_{i} \int_{0}^{l_{i}} \frac{\partial}{\partial x_{i}}\left[\left[\frac{\partial U_{i}\left(x_{i}\right)}{\partial x_{i}}+\frac{1}{2}\left(\frac{\partial W_{i}\left(x_{i}\right)}{\partial x_{i}}\right)^{2}\right] \frac{\partial W_{i}\left(x_{i}\right)}{\partial x_{i}}\right] d x_{i} \delta W_{i}\left(x_{i}\right)+ \\
+E_{i} A_{i} \int_{0}^{l_{i}} \frac{\partial}{\partial x_{i}}\left[\frac{\partial U_{i}\left(x_{i}\right)}{\partial x_{i}}+\frac{1}{2}\left(\frac{\partial W_{i}\left(x_{i}\right)}{\partial x_{i}}\right)^{2}\right] \delta U_{i}\left(x_{i}\right) d x_{i}+ \\
-\left.E_{i} A_{i} \frac{\partial}{\partial x_{i}}\left[\frac{\partial U_{i}\left(x_{i}\right)}{\partial x_{i}}+\frac{1}{2}\left(\frac{\partial W_{i}\left(x_{i}\right)}{\partial x_{i}}\right)^{2} \frac{\partial W_{i}\left(x_{i}\right)}{\partial x_{i}}\right] \delta W_{i}\left(x_{i}\right)\right|_{0} ^{l_{i}}+ \\
-\left.\left[E_{i} A_{i} \frac{\partial U_{i}\left(x_{i}\right)}{\partial x_{i}}+\frac{1}{2}\left(\frac{\partial W_{i}\left(x_{i}\right)}{\partial x_{i}}\right)^{2}\right] \delta U_{i}\left(x_{i}\right)\right|_{0} ^{l_{i}}+ \\
\left.+P \delta U_{1}\left(l_{1}\right)+C\left(\left.\left.\frac{\partial W_{2}\left(x_{2}\right)}{\partial x_{2}}\right|_{x_{2}=l_{2}} ^{-\frac{\partial W_{3}\left(x_{3}\right)}{\partial x_{3}} \mid}\right|_{x_{3}=0}\right)\left(\left.\delta \frac{\partial W_{2}\left(x_{2}\right)}{\partial x_{2}}\right|_{x_{2}=l_{2}}-\left.\delta \frac{\partial W_{3}\left(x_{3}\right)}{\partial x_{3}}\right|_{x_{3}=0}\right)\right\}=0
\end{gathered}
$$

Assuming that virtual displacement: longitudinal $\delta U_{i}\left(x_{i}\right)$ and transversal $\delta W_{i}\left(x_{i}\right)$ for $i=1,2,3$; are arbitrary and independent for $0<x_{i}<l$ the following formulas were obtained: 
equation of displacement in a transversal direction

$$
\left.\left.\begin{array}{c}
E_{i} J_{i} \frac{\partial^{4} W_{i}\left(x_{i}\right)}{\partial x_{i}{ }^{4}}-E_{i} A_{i} \frac{\partial}{\partial x_{i}}\left[\left[\frac{\partial U_{i}\left(x_{i}\right)}{\partial x_{i}}+\frac{1}{2}\left(\frac{\partial W_{i}\left(x_{i}\right)}{\partial x_{i}}\right)^{2}\right]\right. \\
i=1,2,3
\end{array}\right] \frac{\partial W_{i}\left(x_{i}\right)}{\partial x_{i}}\right]=0
$$

equation of displacement in a longitudinal direction

$$
U_{i}\left(x_{i}\right)=-\frac{S_{i} x_{i}}{E_{i} A_{i}}-\frac{1}{2} \int_{0}^{x_{i}}\left[\frac{\partial W_{i}\left(x_{i}\right)}{\partial x_{i}}\right]^{2} d x_{i} \quad i=1,2,3
$$

equation of immutability of the strain along the length of the element

$$
E_{i} A_{i} \frac{\partial}{\partial x_{i}}\left(\frac{\partial U_{i}\left(x_{i}\right)}{\partial x_{i}}+\frac{1}{2}\left[\frac{\partial W_{i}\left(x_{i}\right)}{\partial x_{i}}\right]^{2}\right)=0, \quad i=1,2,3
$$

After integration of equation (5), the axial force is defined as follows:

$$
S_{i}=-E_{i} A_{i}\left(\frac{\partial U_{i}\left(x_{i}\right)}{\partial x_{i}}+\frac{1}{2}\left[\frac{\partial W_{i}\left(x_{i}\right)}{\partial x_{i}}\right]^{2}\right), \quad i=1,2,3
$$

The equation (3) after introducing (6) has the following form:

$$
E_{i} J_{i} W_{i}^{I V}\left(x_{i}\right)+S_{i} W_{i}^{I I}\left(x_{i}\right)=0, \quad i=1,2,3
$$

In equation (7) Roman numerals define the derivatives with respect to space variable $x_{i}$. Inserting the geometrical boundary conditions in the form:

$$
\begin{gathered}
W_{1}(0)=\left.W_{1}^{I}\left(x_{1}\right)\right|_{x_{1}=0}=W_{2}(0)=\left.W_{2}^{I}\left(x_{2}\right)\right|_{x_{2}=0}=\left.0 \quad W_{1}^{I}\left(x_{1}\right)\right|_{x_{1}=l_{1}}=\left.W_{3}^{I}\left(x_{3}\right)\right|_{x_{3}=l_{3}} \\
W_{2}\left(l_{2}\right)=W_{3}(0) \quad W_{1}\left(l_{1}\right)=W_{3}\left(l_{3}\right) \quad U_{1}(0)=U_{2}(0)=0 \\
U_{2}\left(l_{2}\right)=U_{3}(0) \quad U_{1}\left(l_{1}\right)=U_{3}\left(l_{3}\right)
\end{gathered}
$$

Introducing geometrical boundary conditions into equation (2) leads to derivation of the following natural boundary ones: 


$$
\begin{gathered}
\left.E_{1} J_{1} W_{1}^{I I}\left(x_{1}\right)\right|_{x_{1}=l_{1}}+\left.E_{3} J_{3} W_{3}^{I I}\left(x_{3}\right)\right|_{x_{3}=l_{3}}=0 \\
\left.E_{1} J_{1} W_{1}^{I I I}\left(x_{1}\right)\right|_{x_{1}=l_{1}}+\left.P W_{1}^{I}\left(x_{1}\right)\right|_{x_{1}=l_{1}}+\left.E_{3} J_{3} W_{3}^{I I I}\left(x_{3}\right)\right|_{x_{3}=l_{3}}=0 \\
\left.E_{2} J_{2} W_{2}^{I I I}\left(x_{2}\right)\right|_{x_{2}=l_{2}}+\left.S_{2} W_{2}^{I}\left(x_{2}\right)\right|_{x_{2}=l_{2}}-\left.E_{3} J_{3} W_{3}^{I I I}\left(x_{3}\right)\right|_{x_{3}=0}-\left.S_{3} W_{3}^{I}\left(x_{3}\right)\right|_{x_{3}=0}=0 \quad(9 \mathrm{a}-\mathrm{g}) \\
-\left.E_{3} J_{3} W_{3}^{I I}\left(x_{3}\right)\right|_{x_{3}=0}+C\left[\left.W_{3}^{I}\left(x_{3}\right)\right|_{x_{3}=0}-\left.W_{2}^{I}\left(x_{2}\right)\right|_{x_{2}=l_{2}}\right]=0 \\
\left.E_{2} J_{2} W_{2}^{I I}\left(x_{2}\right)\right|_{x_{2}=l_{2}}-C\left[\left.W_{3}^{I}\left(x_{3}\right)\right|_{x_{3}=0}-\left.W_{2}^{I}\left(x_{2}\right)\right|_{x_{2}=l_{2}}\right]=0 \\
S_{2}=S_{3} \quad S_{1}+S_{2}=P
\end{gathered}
$$

The results of numerical calculations are presented in the non-dimensional form on the basis of the following relations:

$$
d_{i}=\frac{l_{i}}{l}, c=\frac{C l}{E_{1} J_{1}+E_{2} J_{2}}, p=\frac{P l^{2}}{E_{1} J_{1}+E_{2} J_{2}}, r_{w}=\frac{E_{3} J_{3}}{E_{2} J_{2}}, r_{m}=\frac{E_{2} J_{2}}{E_{1} J_{1}}, \quad(10 \mathrm{a}-\mathrm{e})
$$

\section{Optimization of the solution}

The modeling of the influence of the particular boundary and initial conditions on the results of the solution requires appliance of methods which are able to automatically perform the selection of the best solution. The genetic algorithms are undoubtedly one of these methods.

The presented method in this paper of solution by means of numerical algorithms in order to browse the space of alternative solutions, allows one to calculate demanded parameters of investigated construction. Genetic algorithms give the possibility to browse a large space of solutions, with much smaller than in classical methods tendency to determine the local optimum [9-11]. This is the reason why the genetic algorithms are used to perform the solution of strongly nonlinear problems.

The algorithm presented in this paper can be described in the following steps $[10,11]$ :

1. Creation of random initial population in the entire range of solution.

2. Genes are coded in the binary form.

3. Selection of population on the basis of the fitness - function by means of a multicriteria selection method (combination of roulette wheel and ranking selection).

4. Addition of the new specimen to parent population.

5. Multicrossing of genes of a parent population created in steps 3 and 4.

6. Mutation of new population with the probability of the $\alpha$ order.

7. Determination of the condition of the optimum solution for the group of the best values of chromosomes. 
After fulfilling the condition of the optimum solution for the group with the best features, the winner is chosen and becomes the required value of the solution of the nonlinear problem.

\section{Numerical results and discussion}

In the presented problem the population size has been set to 1000 . Each value was represented by the number coded by 12 bits ( 12 genes per 1 chromosome). The next parent population was chosen from the half of initial population by means of combination of roulette wheel and ranking selection methods. In the "child" solution, the best parent has been represented by the $1 \%$ in the population without crossover. In the next population the first $10 \%$ of the specimens have been copied without crossover from the previous solution. The new specimens (unrelated) have been represented by $1 \%$ of the population. The remaining part of the population has been created by means of multicrossing ( 4 - points crossing). The mutation has been performed on 100 genes, which were chosen from random chromosomes. The exit condition is presented by the following formula:

$$
\frac{\sum_{i=1}^{l C h r / 2}\left(p_{i}^{R}-p_{M A X}\right)}{l C h r / 2}<2 e-4 \text { and } L P>20
$$

where: $l C h r$ - number of chromosomes, $p_{M A X}$ - required magnitude of the external load (in the presented problem $p_{M A X}$ has been set to 2.4; where the critical loading for the investigated slender system is $\left.p_{c r}=\pi^{2} / 4\right), p_{i}^{R}$ - magnitude of the eternal load for the $i$-th chromosome of population, $L P$ - number of iterations of the genetic algorithm.

At the beginning, the series of numerical calculations were performed in a step by step mode (without automatic optimization). In this mode it is hard to optimize the investigated system because only one parameter may be changed by the user during one series of calculations (for example - for specific crack size the critical force is calculated). The results presented in Figure 3 are concern on relation: critical force $p_{c r}$ versus crack size $c$ for different crack localization $-d_{2}=0.3,0.5,0.7$. These results were obtained in Mathematica software.

It can be concluded that there exists such value of $c$ above which the critical loading of the column is constant. The numerical study shows that $c$ greater than 10 has no influence on critical loading. An important feature of the investigated system is that curves plotted in Figure 3 tend to asymptote $\pi^{2} / 4$.

In Figure 4 curves critical loading versus crack localization have been presented. If $c$ tends to infinity the crack localization has no influence on critical loading. For smaller $c$ (greater crack) the change of crack localization form the fix end to 
the free one results in stabilization of the critical loading. Further reduction of $c$ allows for greater changes in the critical force magnitude regardless of crack localization.

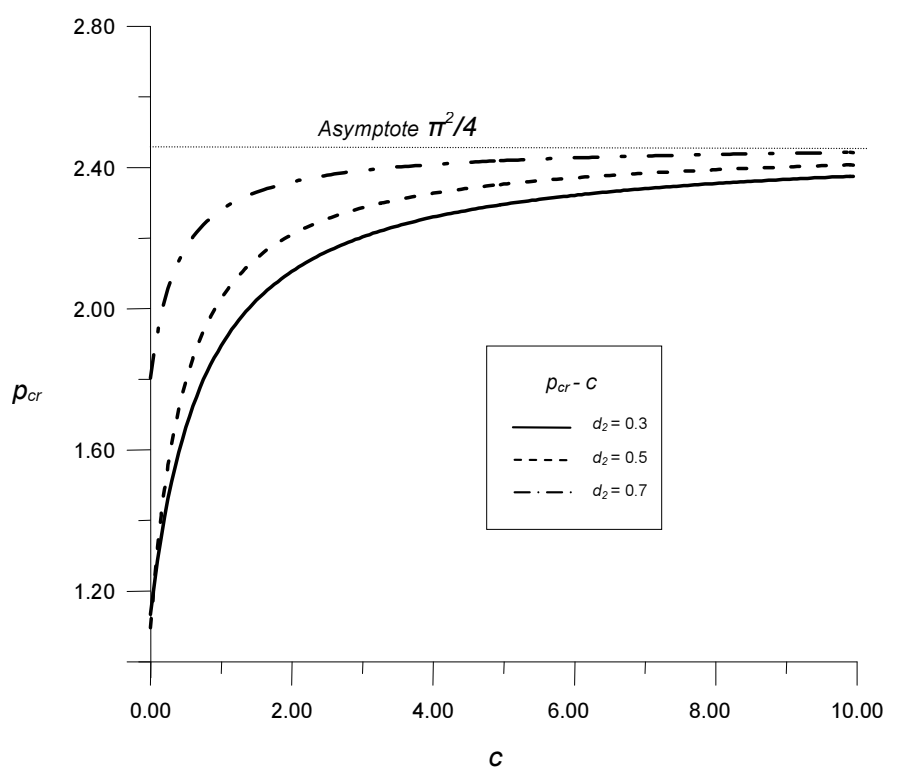

Fig. 3. Influence of crack size on critical loading for different crack localization $\left(r_{\mathrm{m}}=1, r_{\mathrm{w}}=1\right)$

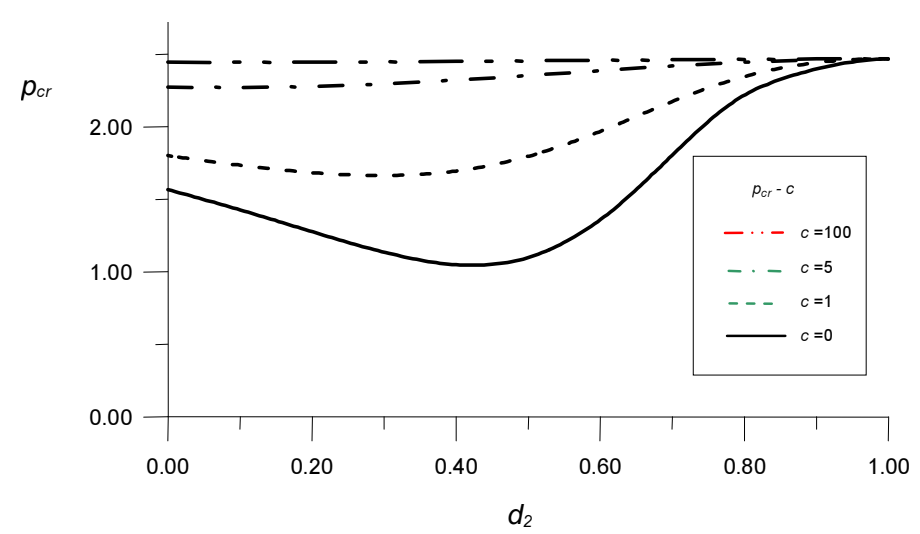

Fig. 4. Influence of crack location on critical loading $\left(r_{\mathrm{m}}=1, r_{\mathrm{w}}=1\right)$

On the basis of the results presented in Figures 5-7, the automatic optimization model has been created. In the first task, the optimum location of the crack has been investigated for given magnitude of external load $p=2.4$ and crack size $c=0$, 1, 5, 10. The results were plotted in Figure 5. 


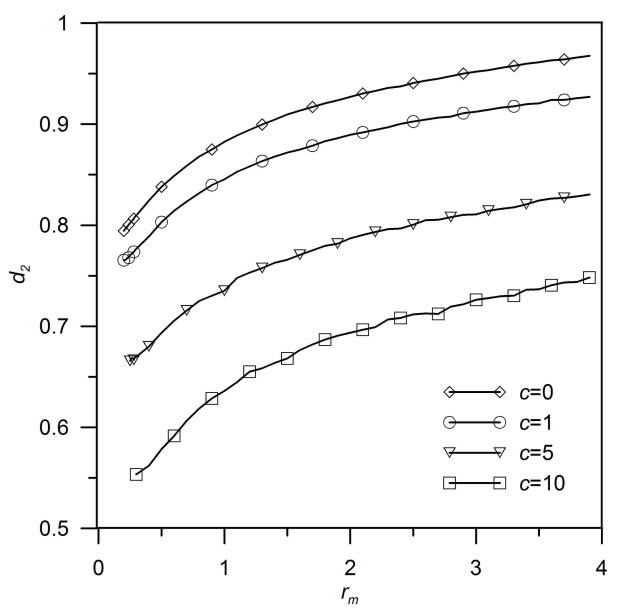

Fig. 5. Optimum crack location in relations to crack size and flexural rigidity ratio $\left(r_{\mathrm{w}}=1\right)$

For a given magnitude of external load, a different crack size and flexural rigidity factor $r_{\mathrm{m}}$ the optimization of crack location has been performed. It has been concluded that the greater $c$ causes the extension of the range at which the crack may appear (the column is able to transfer given external load). For the whole crack range the increase of the magnitude of flexural rigidity factor results in the increase of the minimum crack location.

In the second task, the optimum size of the crack for desired external load magnitude $p=2.4$ and crack location $d_{2}=0.25,0.5,0.75$ has been investigated.

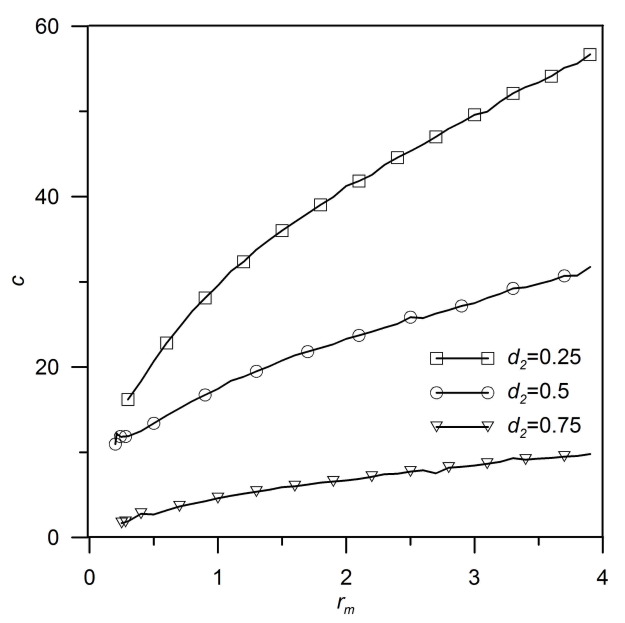

Fig. 6. Optimum crack size in relations to crack location and flexural rigidity ratio $\left(r_{\mathrm{w}}=1\right)$

For a given magnitude of external load, different crack location and flexural rigidity factor $r_{\mathrm{m}}$ the optimization of the crack size has been performed. After 
analysis of the results of numerical calculations obtained from the computer program created by the authors, it can be concluded that when the crack is localized near the fix end the small tolerance on the crack size for given external load has been observed, especially for the systems with high flexural rigidity factor.

In the third case, the minimum magnitudes of external load and crack location have been investigated for crack size $c=1,5,10$. The results have been plotted in the figure below in the range of external load 0.5-2.4. The analysis of the curves presented in the Figure 7 allows one to predict the capacity of the system while the crack initiation/propagation takes place. For example, in the case for $c=1$, the change in crack location from the free end in the direction of the support causes the reduction of the maximum external load.

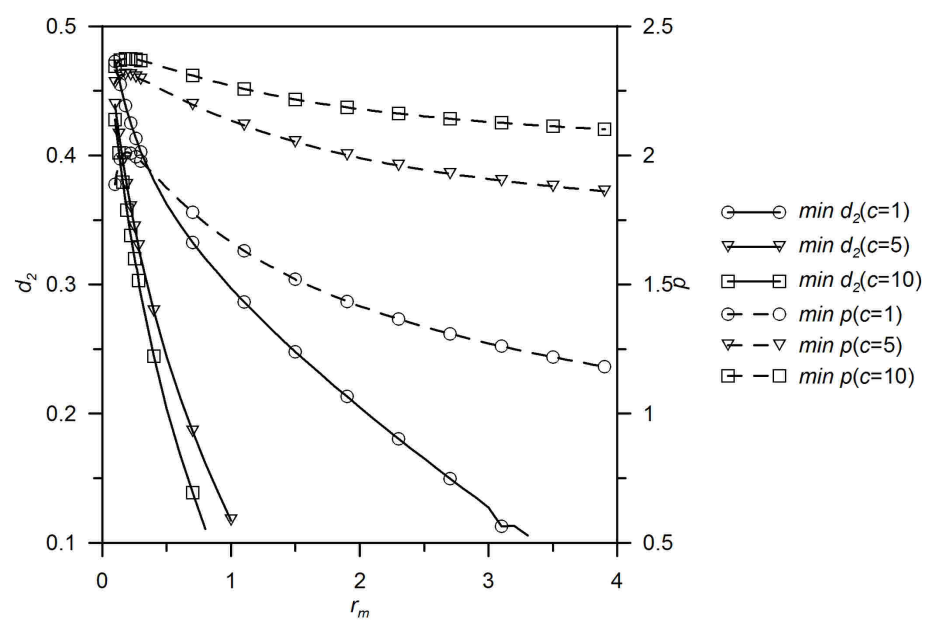

Fig. 7. The minimum magnitudes of external load and crack location for different crack size $\left(r_{\mathrm{w}}=1\right)$

Greater crack size causes high capacity drop. While $r_{\mathrm{m}}>1$ the reduction of the maximum external load magnitude is being observed regardless to crack size and/or location.

\section{Conclusions}

An implementation of genetic algorithms allows one to optimize systems taking into account more parameters during one calculation process. The reduction of time which is needed to find the optimum parameters of the investigated system has been achieved. Genetic algorithms with a high level of population allow one to minimize the risk occurrence of local minimum with respect to analytical methods. It can be concluded than the genetic algorithms are very useful tool for the engineer for optimization of the shape and mechanical properties of the systems with a wide range of applications. 


\section{References}

[1] Kukla S., Free vibration and stability of stepped columns with cracks, Journal of Sound and Vibration 2009, 319, 1301-1311.

[2] Wang C.Y., Buckling of an internally hinged column with an elastic support, Engineering Structures 2002, 24, 1357-1360.

[3] Przybylski J., Drgania i stateczność dwuczłonowych układów prętowych wstępnie sprężonych przy obciążeniach niezachowawczych, Częstochowa 2002.

[4] Tomski L., Uzny S., Vibration and stability of geometrically nonlinear column subjected to generalized load with a force directed toward the positive pole, International Journal of Structural Stability and Dynamics 2008, 8, 1-24.

[5] Bouchard P.O., Bay F., Chastel Y., Numerical modelling of crack propagation: automatic remeshing and comparison of different criteria, Computer Methods in Applied Mechanics and Engineering 2003, 192, 3887-3908.

[6] Pierrès E., Baietto M.C., Gravouil A., A two-scale extended finite element method for modelling 3D crack growth with interfacial contact, Computer Methods in Applied Mechanics and Engineering 2010, 199, 1165-1177.

[7] Rannou J. et al, Three dimensional experimental and numerical multiscale analysis of a fatigue crack, Computer Methods in Applied Mechanics and Engineering 2010, 199, 1307-1325.

[8] Yongyong H., Dan G., Fulei Ch., Using genetic algorithms to detect and configure shaft crack for rotor-bearing system, Computer Methods in Applied Mechanics and Engineering 2001, 190, 5895-5906.

[9] Cekus D., Posiadała B., Vibration model and analysis of three-member telescopic boom with hydraulic cylinder for its radius change, International Journal of Bifurcation and Chaos 2011, 21, 2883-2892.

[10] Hollad J.H., Adaptation in Natural and Artificial Systems, University of Michigan Press, 1975.

[11] Michalewicz Z., Genetic Algorithms + Data Structures = Evolution Programs, Springer Verlag, Berlin 1996. 